\title{
CHEMICAL CHARACTERIZATION OF MICROPARTICLES BY LASER ABLATION IN AN ION TRAP MASS SPECIROMETER
}
J. M. Dale, W. B. Whitten, and J. M. Ramsey
Analytical Chemistry Division
Oak Ridge National Laboratory
DE9 1014258
Oak Ridge, TN 37831-6142

CONF-9104192--10

We are developing a new technique for the chemical characterization of microparticles based upon the use of electrodynamic traps. The electrodynamic trap has achieved widespread use in the mass spectrometry community in the form of the ion trap mass spectrometer or quadrupole ion trap (1). Small macroscopic particles (microparticles) can be confined or levitated within the electrode structure of a three-dimensional quadrupole electrodynamic trap in the same way as fundamental charges or molecular ions by using a combination of ac and dc potentials (2). Our concept is to use the same electrode structure to perform both microparticle levitation and ion trapping/mass analysis. The microparticle will first be trapped and spatially stabilized within the trap for characterization by optical probes, i.e., absorption, fluorescence, or Raman spectroscopy. (We have previously shown that such spectroscopic probes can be extremely sensitive, e.g., a detection limit of one molecule of Rhodamine-6G has been determined in the case of fluorescence spectroscopy (3), (4)). After the particle has been optically characterized, it is further characterized using mass spectrometry. Ions are generated from the particle surface using laser ablation or desorftion. The characteristics of the applied voltages are changed to trap the ions formed by the laser with the ions subsequently mass analyzed. The work described here focuses on the ability to perform laser desorption experiments on microparticles contained within the ion trap. Laser desorption has previously been demonstrated in ion trap devices by applying the sample to a probe which is inserted so as to place the sample at the surface of the ring electrode (5), (6). Our technique requires the placement of a microparticle in the center of the trap. Our initial experiments have been performed

Research sponsored by U.S. Department of Energy, Office of Basic Energy Sciences, under contract DE-AC05-84OR21400 with Martin Marietta Energy Systems, Inc.

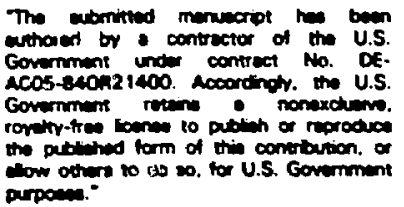


on falling microparticles rather than levitated particles to eliminate voltage switching requirements when changing from particle to ion trapping modes.

Figure 1 shows a schematic diagram of our current apparatus for performing these experiments. The ion trapping device is a modified Finnigan MAT Model 800 Ion Trap Detector (ITD). The trapping electrodes were removed from the ITD vacuum chamber and placed in a 6-inch cube with the rotational symmetry axis of the trap oriented vertically. The cube is attached to a 4-inch oil diffusion pump. The tf voltage from the ITD was reattached to the ring electrode by extending the transformer tap wire to a high-voltage vacuum feedthrough mounted on one of the side ports and retuning the transformer for resonance. The ITD was operated with nominally 1 mtorr of $\mathrm{He}$ buffer gas as usual. The ion lens assembly normally used for electron-impact ionization was removed from the top end cap and a particle dropping device was installed. The particle dropper consisted of a funnel-shaped container with a $450-\mu \mathrm{m}$ spout. A $300-\mu \mathrm{m}$ wire attached to a $6-\mathrm{mm}$ rod normally rests in the spout. The rod exits the vacuum chamber through an o-ring-sealed fitting. Particles of interest are placed in the container and dispensed by moving the wire attached to the rod. The other three side ports are fitted with 6-inch pyrex windows while the bottom port is covered with a flange mounted with the channeltron electron multiplier. A 5-mW HeNe laser beam is focused into the un through the windows and opposing 3-mm holes drilled in the ring electrode. The HeNe beam is positioned $\approx 1 \mathrm{~mm}$ above the center of the trap. The second harmonic laser radiation frcm a pulsed Nd:YAG laser (Quanta-Ray DCR-2A) propagates in the opposite direction through the trap and is focused by a $1-\mathrm{m}$ lens at the trap center.

Collection of a laser desorption mass spectrum requires synchronization of the Nd:YAG laser with the falling particle and the ITD. The ITD runs continuously through its normal scan sequence of trapping and mass-selective particle ejection. The ITD can have a tranping-mode duty cycle of $-40 \%$ if appropriate scan settings are used. When particles are dropped they pass through the HeNe probe beam scattering light that is detected by the photodiode. The photodiode signal is converted to TTL, then ANDed with the electron gate signal from the ITD. If a light scattering signal is detected when the ITD is in the trapping 


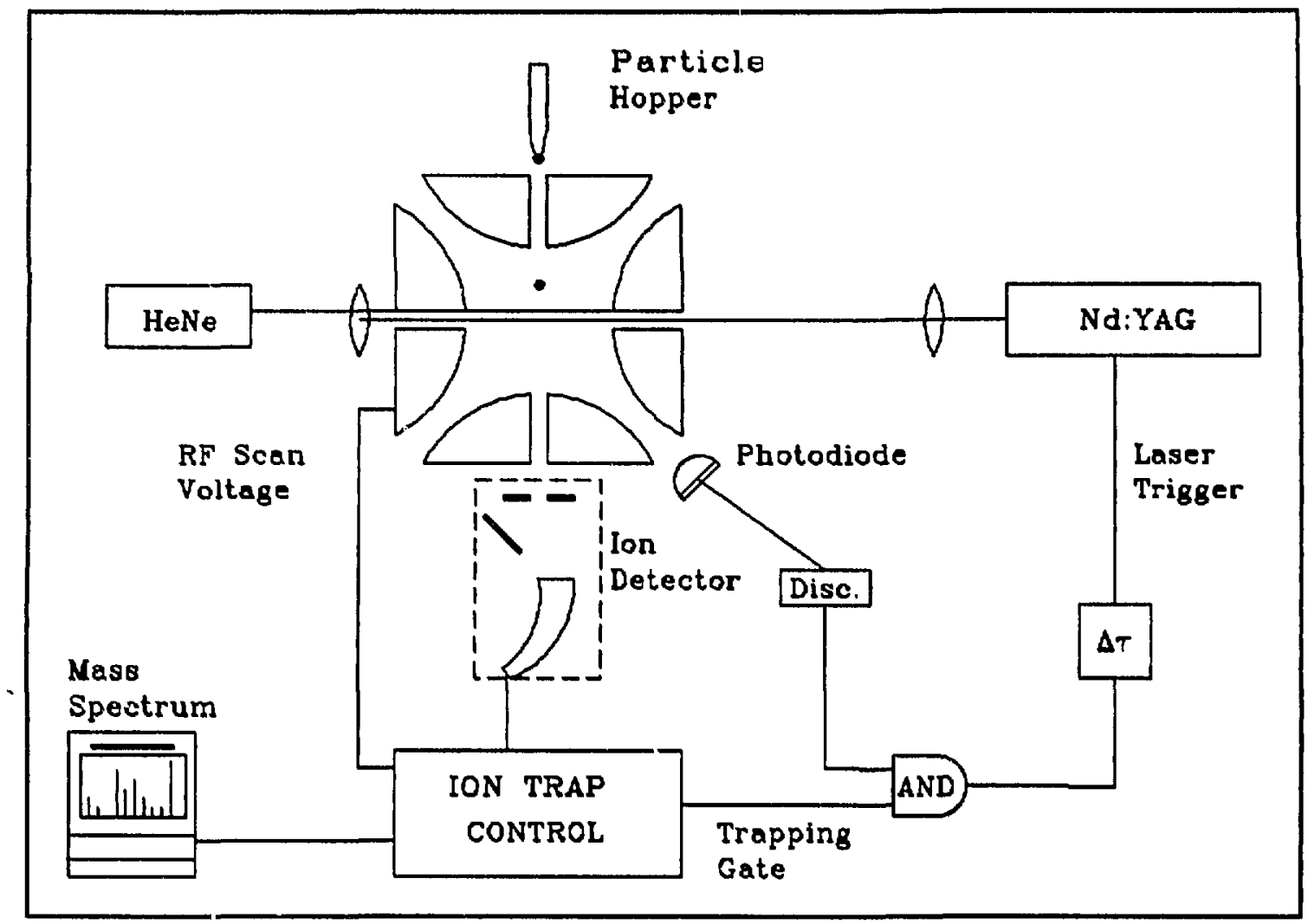

\section{Figure 1}

mode, the Nd:YAG laser is fired after an adjustable delay time. The laser trigger delay allows for the spatial displacement between the HeNe and Nd:YAG beams. Particles can be reliably illuminated with the 10 -ns pulse from the Nd:YAG laser after proper alignment.

Silicon carbide particles (nominal $125-\mu \mathrm{m}$ diameter) coated with various materials were used in our initial studies. Particles were coated with various quaternary ammonium or phosphonium salts by dissolving them in methanol, combining with a given mass of particles and evaporating the solvent. In all cases $5 \mathrm{mg}$ of salt was evaporated onto $5 \mathrm{gm}$ of particles. This loading would result in roughly 10 monolayers of material on the surface of a particle based upon particle surface area measurements. Compounds investigated include trimethylphenylammonium chloride, triethylphenylammonium iodide, tetrabutylammonium iodide, and tetraphenylphosphonium bromide. All experiments were performed with pulse energies of $\approx 1 \mathrm{~mJ}\left(10^{9} \mathrm{~W} / \mathrm{cm}^{2}\right)$ except where noted. Ions were reliably produced from 
dropped particles with yield correlating with the intensity of the 532-nm light scattered by the particle as detected by the photodiode. The quality of the mass spectra varied primarily due to what appears to be space charge effects. Mass specta of the above compounds all produced intact cations and expected fragment ions. The mass spectra compare favorably with those of Ref. 6 and SIMS data on the same particles.

In addition to the above coated $\mathrm{SiC}$ particles, uncoated particles of $\mathrm{SiC}, \mathrm{Fe}$, and $\mathrm{Nb}$ were also investigated. The uncoated $\mathrm{SiC}$ particles yielded $\mathrm{Na}$ and $\mathrm{K}$ ions presumably due to surface contamination. No ions were observed that would be associated with $\mathrm{SiC}$ even at intensities of $10^{10} \mathrm{~W} / \mathrm{cm}^{2}$. The iron and niobium particles required slightly higher energies $(\approx 3 \mathrm{~mJ} / \mathrm{pulse}$ ) to yield ions as would be expected. The iron spectra included the iron isotopes in addition to showing a copper impurity. The $\mathrm{Nb}$ spectra also indicated some iron contamination.

Improvements in the current apparatus promise to yield good sensitivity for materials on the surface of microparticles. Submonolayer sensitivities should easily be achieved. Excess ion production leading to space charge effects in the trap is currently more of a problem than lack of signal. Combining particle levitation with ion trapping may allow multiple desorption experiments to be performed on a single particle and thus permit signal averaging.

\section{ACKNOWLEDGEMENTS}

Research sponsored by U.S. Department of Energy, Office of Basic Energy Sciences, under contract DE-AC05-84OR21400 with Martin Marietta Energy Systems, Inc.

1. R. E. March and R. J. Hughes, Quadrupole Storage Mass Spectrometry, Vol. 102, "Chemical Analysis", J. D. Winefordner, Ed., Wiley-Interscience, NY, 1989.

2. R. F. Wuerker, H. M. Goldenberg, and R. V. Langmuir, J. Apph. Phys. 30 , 441 (1959). 
3. W.B. Whitten, J.M. Ramsey, S. Arnold, and B.V. Bronk, Proceedings of the 1989 Scientific Conference on Obscuration and Aerosol Research, CRDEC-SP-026, pg. 45, (1990).

4. W.B. Whitten, J.M. Ramsey, S. Arnold, and B.V. Bronk, Anal. Chem. 63, 1027 (1991).

5. D.N. Heller, I. Lys, R.J. Cotter, and O.M. Uy, Anal Chem., 61, 1083 (1989).

6. G.L. Glish, D.E. Goeringer, K.G. Asano, and S.A. McLuckey, Int. J. Mass Spectrom. \& Ion Proc., 94, 15 (1989).

\section{DISCLAIMER}

This report was prepared as an account of work sponsored by an agency of the United States Government. Neither the United States Government nor any agency thereof, nor any of their employees, makes any warranty, express or implied. or assumes any legal liability or responsibility for the accuracy, completeness, or usefulness of any information, apparatus, product, or process disclosed, or represents that its use would not infringe privately owned rights. Reference herein to any specific commercial product, process, or service by trade name, trademark, manufacturer. or otherwise does not necessarily constitute or imply its endorsement, recommendation, or favoring by the United States Government or any agency thereof. The views and opinions of authors expressed herein do not necessarily state or reflect those of the United States Government or any agency thereof. 